\title{
Authors' response to Young and Hopkins: vitamin D and lung function
}

We thank Dr RP Young and Ms RJ Hopkins for their interest in our article and their constructive comments. ${ }^{1}$

We agree with Dr RP Young and Ms RJ Hopkins that our analyses may suggest a threshold effect. However, we believe that more studies are needed before we firmly can assume a threshold effect. It is true that that the association between vitamin $\mathrm{D}$ level and $\mathrm{FEV}_{1} \%$ predicted was mirrored by a corresponding association between vitamin $\mathrm{D}$ and $\mathrm{FVC} \%$ predicted. Therefore in our main analysis, the vitamin D level was not significantly associated with the $\mathrm{FEV}_{1} / \mathrm{FVC}$ ratio. This general reduction of lung volumes in 
individuals with low vitamin D levels could, as suggested by Young and Hopkins, be caused by general frailty or weakness and not by an intrapulmonary process. Yet, as we observed a significant interaction, suggesting a stronger association between vitamin $\mathrm{D}$ and $\mathrm{FEV}_{1} \%$ pred in individuals with airway obstruction we concluded that low vitamin D levels may play a role with regard to development and in particular progression of COPD. ${ }^{2}$ It was not our intent to claim that low vitamin D is a cause of decreased lung function, as observational studies like ours are subject to reverse causation and confounding as rightly pointed out by Young and Hopkins. We rather sought to report the observed association and fully agree that these associations could be confounded by or mediated through, for example, systemic inflammation. Indeed, we ourselves have previously reported that markers of systemic inflammation like elevated fibrinogen and $\mathrm{C}$ reactive protein are associated with reduced lung function, increased risk of COPD and prognosis in COPD. ${ }^{3-5}$ Therefore, we agree that future studies on the relationship between vitamin $\mathrm{D}$ and lung function and COPD should include possible confounding or mediation through systemic inflammation.

\section{Shoaib Afzal, ${ }^{1,2}$ Peter Lange, ${ }^{2,3,4,5}$ \\ Stig E Bojesen, ${ }^{1,2,3,6}$ Jacob J Freiberg, ${ }^{1,2}$ \\ Børge G Nordestgaard ${ }^{1,2,3,6}$}

${ }^{1}$ The Department of Clinical Biochemistry, Herlev Hospital, Copenhagen University Hospital, Herlev, Denmark

${ }^{2}$ The Copenhagen General Population Study, Herlev Hospital, Copenhagen University Hospital, Herlev, Denmark

${ }^{3}$ The Copenhagen City Heart Study, Frederiksberg Hospital, Copenhagen University Hospital, Copenhagen, Denmark

${ }^{4}$ Faculty of Health and Medical Sciences, Department of Public Health, Section of Social Medicine, University of Copenhagen, Herlev, Denmark

${ }^{5}$ Section of Respiratory Medicine, Hvidovre Hospital, Copenhagen University Hospital, Herlev, Denmark ${ }^{6}$ Faculty of Health and Medical Sciences, University of Copenhagen, Herlev, Denmark

Correspondence to Professor Børge $\mathrm{G}$ Nordestgaard, Department of Clinical Biochemistry, Herlev Hospital, Copenhagen University Hospital, Herlev Ringvej 75 , Herlev DK-2730, Denmark; Boerge.Nordestgaard@ regionh.dk

Contributors $S A$ and BGN drafted the response, which was amended and finally approved by PL, SEB and JJF.

Competing interests PL received during the last 5 years pharmaceutical company grants from GSK in 2010 and 2011, Boehringer-Ingelheim and Almirall in 2012 via his home institution and also participated in speaking activities, industry advisory committee or other related activities sponsored by Almirall, Boehringer-Ingelheim, Novartis, GSK, AstraZeneca, Pfizer, Mundipharma and UCB during the period 2008-2012.
Provenance and peer review Not commissioned; internally peer reviewed.

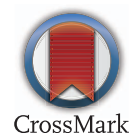

To cite Afzal S, Lange P, Bojesen SE, et al. Thorax 2014;69:770-771.

Received 13 January 2014

Accepted 16 January 2014

Published Online First 7 February 2014

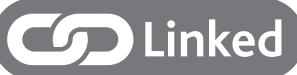

- http://dx.doi.org/10.1136/thoraxjnl-2013-203682

- http://dx.doi.org/10.1136/thoraxjnl-2014-205101

Thorax 2014;69:770-771.

doi:10.1136/thoraxjnl-2014-205133

\section{REFERENCES}

1 Young RP, Hopkins RJ. Vitamin D and lung function. Thorax 2014;69:769-70.

2 Afzal S, Lange P, Bojesen SE, et al. Plasma 25-hydroxyvitamin $D$, lung function and risk of chronic obstructive pulmonary disease. Thorax 2014;69:24-31.

3 Dahl M, Tybjaerg-Hansen A, Vestbo J, et al. Elevated plasma fibrinogen associated with reduced pulmonary function and increased risk of chronic obstructive pulmonary disease. Am J Respir Crit Care Med 2001;164:1008-11.

4 Dahl $\mathrm{M}$, Vestbo J, Lange $\mathrm{P}$, et al. C-reactive protein as a predictor of prognosis in chronic obstructive pulmonary disease. Am J Respir Crit Care Med 2007;175:250-5.

5 Dahl M, Vestbo J, Zacho J, et al. C reactive protein and chronic obstructive pulmonary disease: a Mendelian randomisation approach. Thorax 2011;66:197-204. 